\title{
NARRATIVAS, IDENTIDADES E AÇÃO POLÍTICA NA PÓS-MODERNIDADE
}

\author{
Andrea Machado de Almeida Mattos \\ Enxergar além das diferenças do outro é encontrar a ma- \\ neira de trilharem juntos o caminho.
}

(Rachel Naomi Remen ${ }^{1}$ )

\begin{abstract}
RESUMO: Este trabalho procura explorar o recente interesse pela pesquisa qualitativa de natureza narrativa, discutindo as relações entre narrativa e formação e/ou compreensão da identidade. $\mathrm{O}$ objetivo principal deste trabalho é tentar estabelecer um diálogo entre o pensamento de pesquisadores que abordam as narrativas ou histórias de vida como constitutivas de nossas identidades e o pensamento de autores que abordam a questão identitária a partir de um ponto de vista pós-moderno. Por meio de um exemplo de "Terceiro Espaço", as ideias e propostas desses autores serão discutidas a fim de se alcançar uma compreensão maior sobre questôes tão atuais quanto polêmicas, quais sejam narrativas, identidades e culturas, em suas definiçōes mais amplas.

Palavras-chave: Narrativas. Identidades. Pós-modernidade. Terceiro espaço.
\end{abstract}

NARRATIVES, IDENTITIES AND POLITICAL ACTION IN POST-MODERNITY

ABSTRACT: This paper aims to consider the recent interest in a type of qualitative research known as narrative research, discussing the relationship between narrative and identity formation and/or understanding. The main objective is to try to establish a

Mestre em Estudos Linguísticos e professora assistente da Faculdade de Letras da Universidade Federal de Minas Gerais (UfGM).E-mail: andreamattos@ufmg.br 
link between the ideas of researchers who deal with the issue of narratives or life stories as identity construction and the ideas of authors who approach the identity issue from a post-modern point of view. Through an example of "Third Space", the ideas and suggestions of these authors will be discussed in order to try to reach a deeper comprehension of such current - as well as polemic - issues as narratives, identities and cultures, in their broadest definitions.

Key words: Narratives. Identities. Post-modernity. Third space.

ecentemente, a pesquisa em várias áreas assumiu uma perspectiva mais qualitativa. Por essa razão há um crescente interesse pelo chamado "modo narrativo de pensamento e expressão" (Bruner, 1986). ${ }^{2}$ A chamada "Virada Narrativa" tem influenciado as ciências humanas e sociais, e a pesquisa nessa linha metodológica cobre uma variedade de tópicos, desde a ficção a modos narrativos para a compreensão da experiência humana. De acordo com Fivush (2006a), esse crescente interesse se originou a partir do trabalho de importantes teóricos: o psicólogo e filósofo americano William James (1842-1910) falava de dois modos de pensamento, o paradigmático e o modo narrativo. Mais recentemente, o psicólogo cognitivista Jerome Bruner (1986) referiu-se a "modos narrativos de conhecimento" e descreveu narrativas como histórias, dramas e relatos históricos que enfatizam a intenção e a ação humanas.

Explorando essa atual tendência narrativa, este trabalho parte do objetivo de tentar estabelecer um diálogo entre o pensamento de Bruner e outros pesquisadores, que abordam as narrativas ou histórias de vida como constitutivas de nossas identidades, e o pensamento de autoras como Nicholson (1995), Mohanty (1995), Patton (1995) e Mouffe (1995), que abordam a questão identitária a partir do ponto de vista pós-moderno. Tenta-se, ainda, prolongar esse diálogo para estabelecer uma possível relação com as sugestões de Wilber (2005, 2007) para compreender a espiritualidade (ou religião) humana. Outros autores também serão discutidos a fim de se alcançar uma compreensão maior sobre questôes tão atuais quanto polêmicas, quais sejam narrativa, identidade e cultura, em suas definições mais amplas. 
Narrativas e identidades: uma relação recíproca

Para Bruner (2002, p. 16), o homem tem a "capacidade de organizar e comunicar sua experiência de forma narrativa". De acordo com o autor, é na construção de histórias e mitos, e ao ouvir as histórias de outrem, que lidamos com nossa experiência e fazemos sentido de nossa realidade. $\mathrm{Na}$ visão do autor, histórias que têm início, meio e fim nos fornecem modelos que contextualizam a informação que processamos (Barry, 2006). Narrativas e histórias são, assim, de acordo com Bruner (1990), uma forma de pensamento, uma forma de organizar a experiência humana. Para ele, as histórias nos "fornecem modelos do mundo" (2002, p. 25). Segundo Bruner (1990, 2002), é por meio das narrativas que nos constituímos, que nos transformamos na pessoa que somos, ou seja, é por intermédio das histórias que nos contam e das histórias que contamos, inclusive sobre nós mesmos, que nos formamos e nos transformamos a cada dia, continuamente.

Fivush, que atualmente pesquisa como as crianças aprendem a interagir por intermédio de narrativas e a maneira como o "Eu"3 da criança é formado e influenciado pelo ouvir e contar histórias, acredita que "narrativas são a maneira por meio da qual compreendemos e fazemos sentido de nossas experiências diárias, e esse processo ocorre nas interaçōes sociais" (Fivush, 2006a). A autora também afirma que, "à medida que falamos sobre nossas experiências, nós reinterpretamos, reavaliamos e reconstruímos nossas experiências" (idem, ibid.). Ela diz ainda que "narrativas são maneiras socialmente construídas de compreender o que uma vida é e o que uma pessoa é" (idem, 2006b). E acrescenta:

Narrativas vão além da simples descrição de eventos experienciados para fornecer modelos explicativos e avaliaçăo emocional sobre o que esses eventos significam para o indivíduo. Mais especificamente, narrativas permitem-nos criar uma realidade compartilhada. Ao contar as histórias da nossa vida, estamos contando quem somos e estamos compartilhando nossa visão de mundo. Nós não apenas contamos o que aconteceu; nós explicamos como e por que esses eventos aconteceram, como nós nos sentimos e como reagimos a eles e o que eles significam para nós. (Idem, ibid.)

Assim, como esclarece Bruner (2002, p. 25), compartilhar "histórias comuns cria uma comunidade interpretativa" que promove a coesão cultural. Bruner (1990, p. 11) define cultura como "sistemas simbólicos compartilhados" e "formas tradicionalizadas de viver 
e trabalhar conjuntamente". O autor afirma que a cultura é "o principal fator que dá forma às mentes daqueles que vivem sob seu domínio" (idem, p. 12). Para ele, é a cultura e a busca por significação que moldam e guiam a natureza mutante da espécie humana. E é por meio das narrativas que o ser humano atinge "a capacidade não apenas de marcar aquilo que é culturalmente canônico, mas também de dar conta de desvios que podem ser incorporados pelas narrativas" (idem, p. 68). Narrativas e cultura estão, assim, intimamente ligadas, num eterno jogo dialético (Bruner, 2002).

As ideias de Bruner $(1990,2002)$ claramente se contrapõem à concepção "essencialista" do ser humano, que considera o "Eu", ou nossa identidade, uma essência, algo "preexistente ao nosso esforço de descrevê-lo" (1990, p. 99). Para Bruner, nosso "Eu”, nossa identidade, nada mais é que uma construção, "um conceito criado pela reflexão, da mesma forma que construímos outros conceitos" (idem, p. 100). Além disso, como vimos, nosso "Eu" é constantemente criado e recriado por meio de nossas narrativas, nossas histórias de vida (Bruner, 2002). Bruner ressalta, ainda, que nossa identidade é "profundamente relacional" (idem, ibid., p. 86), isto é, nosso "Eu” é também constituído pelo "outro" por meio de nossas (inter)relações sociais. Segundo ele, por meio da nossa capacidade de narrar, produzimos nosso "Eu", "que nos une aos outros" e que reflete nossa cultura dialeticamente (idem, ibid.).

Coracini (2007, p. 9) entende a identidade como formada por interdiscursos, que são, na verdade, "fragmentos de múltiplos discursos que constituem a memória discursiva" do ser humano, recebida como herança e continuamente modificada e transformada justamente nas nossas relações com o outro, numa imbricada rede de inter-relações, ao mesmo tempo constituída e constituidora de nossos valores, crenças, ideologias e culturas. Segundo a autora, então, esses interdiscursos constituem inúmeras vozes que formam a nossa visão do mundo, e dialeticamente também são formadas por ela. É isso que nos torna, como seres humanos, a um só tempo semelhantes e diferentes de outros seres humanos. Bruner (2002, p. 85) também se refere às nossas "múltiplas vozes interiores”, lembrando que cada um de nós é fragmentado e complexo, um conjunto de personagens, ao mesmo tempo em que somos únicos em nossa complexidade. Apesar disso, como nos mostra Coracini (op. cit., p. 9), "cada um de nós tem a ilusão de que tem uma [única] identidade, inventada pelo outro e assumida como sua”. 
Essa concepção não essencialista da nossa identidade como algo fragmentado, múltiplo e heterogêneo, híbrido na concepção de Bhabha (cf. Rutherford, 1990; Chance, 2007), está no cerne das discussões pós-modernas sobre identidade. É essa concepção pós-moderna que traz novas propostas para as lutas políticas atuais e que nos permite visualizar um futuro mais promissor para o papel da educação no mundo de hoje.

\section{Identidades na pós-modernidade}

A cultura ocidental, tal como é por nós conhecida, está amplamente baseada no culto à racionalidade, na celebração da coerência do pensamento e das ações, na valorização da disciplina e da ordem, em nome da homogeneidade, da igualdade entre todos e da inclusão, indistintamente. Contudo, como afirma Coracini (2007), nossa cultura ocidental, ao tentar incluir a todos e proporcionar a todos uma desejada igualdade, na verdade prima pela exclusão e pela desigualdade. Foi nesse contexto que surgiram as chamadas lutas identitárias, ou seja, a luta política por direitos iguais para todos. Essas lutas foram - e ainda são - travadas por movimentos identitários que, segundo Nicholson e Seidman (1995, p. 8), "mantiveram o legado do modernismo, naturalizando ou essencializando as categorias de identidade". Em outras palavras, esses movimentos identitários se baseavam na concepção de identidade como essência, como unicidade. Para os defensores desses movimentos, cada pessoa tem a sua identidade, que é única, individual e indivisível. Assim, surgiram os movimentos negros, feministas e de homossexuais. Esses movimentos buscam alcançar, para seus membros, direitos que a eles são negados pela sociedade em geral. Exercem, assim, uma ação política em benefício de seus membros, ou seja, daqueles que compartilham da mesma identidade defendida pelo grupo.

Dentro de uma visão pós-moderna do conceito de identidade, porém, surgem propostas para uma ação política mais ampla, buscando transformar o que hoje se entende por "político" (Nicholson \& Seidman, 1995). Contudo, na visão de Nicholson e Seidman (1995, p. 9), "transformar conceitos atuais sobre 'o político' não é equivalente a abandonar a política completamente”. Pelo contrário, significa compreender a ação política de forma totalmente diferente, sob uma nova concepção de seus objetivos. 
Segundo Nicholson (1995), essas lutas identitárias que dominaram o cenário político da segunda metade do século XX se baseiam na ideia de que o caráter, ou a personalidade, do ser humano emana da sua constituição biológica e de que a imagem que cada pessoa tem de si, ou seja, sua identidade, não pode fugir desse "determinismo biológico". A autora vai além e chama de "fundamentalismo biológico" (p. 42) a posição de alguns autores, principalmente teóricos feministas do final do século Xx, ou da chamada "segunda onda" do feminismo, que embora "aceitem a ideia de que o caráter é socialmente formado (...) não necessariamente rejeitam a ideia de que a biologia é o local da formação do caráter" (p. 41). Em outras palavras, embora esses autores compartilhem da ideia de que a identidade humana é formada social e culturalmente e de que essa influência social e cultural gera diferenças nas experiências individuais, num nível bem básico, esses autores também acreditam que aquilo que nos foi dado biologicamente é responsável por certas reaçôes dos indivíduos às influências sociais e culturais, tornando essas reações constantes, mesmo quando sociedades e culturas absolutamente diferentes são comparadas. Nicholson ressalta, em relação à compreensão do significado do termo "mulher", já que ela fala a partir de um ponto de vista feminista embora pós-moderno -, que a posição desses autores que se alinham com algum tipo de fundamentalismo biológico não leva em conta as diferentes experiências vividas por diferentes grupos de mulheres. Ao considerarem que apenas o fato de se ter nascido "mulher", ou seja, apenas o fato de se possuir um corpo biologicamente feminino, tornaria todas as mulheres do mundo iguais, em oposição a tudo o que é masculino, esses autores não consideram as diferenças contextuais, sociais e culturais experienciadas por cada mulher. A autora chama atenção para o perigo de tal generalização, que advém de uma abordagem "dualista" (homem x mulher; negro x branco; pobre x rico etc.) da questão da identidade. Nicholson (1995, p. 43) cita a feminista Elizabeth Spelman (1988) para explicar tal abordagem dualista para o sexismo e o racismo:

[T] odas as mulheres são oprimidas pelo sexismo; algumas mulheres são ainda oprimidas pelo racismo. Tal análise distorce as experiências de opressão de mulheres Negras [sic] por não notar importantes diferenças entre os contextos em que mulheres Negras e mulheres brancas experienciam o sexismo. ${ }^{4}$ 
Nicholson (op. cit., p. 44) ressalta que essa tendência para interpretar a "identidade sexual como dada, como básica e comum interculturalmente", é muito poderosa. Porém, para a autora, essa concepção é "produto de um sistema de crenças específico das sociedades ocidentais modernas" (idem, ibid.). O que ela defende, no entanto, é exatamente a posição oposta: "de que a biologia não pode ser usada para embasar afirmaçôes sobre 'mulheres' ou 'homens' transculturalmente" (1995, p. 49). Isso porque, como explica Nicholson, qualquer definição de características femininas fixas ou essenciais "tende a refletir a perspectiva daqueles que fazem as caracterizações” (p. 54), mesmo quando essas características essenciais são aceitas como socialmente construídas. Por exemplo, as crenças de que as mulheres são mais relacionais do que os homens, ou de que as mulheres são mais aptas a cuidar e nutrir, ao passo que os homens são mais agressivos e competitivos, são, do ponto de vista da autora, ideias generalizadas indistintamente a partir de uma concepção ocidental sobre o significado de ser mulher.

É nesse ponto que Nicholson (1995) dialoga com Bruner (1990, 2002). Ao afirmar que essa caracterização essencialista da identidade feminina - em oposição à masculina - é um produto das sociedades ocidentais modernas, Nicholson assume, como Bruner, exatamente o ponto de vista oposto, ou seja, aquele de que nossas identidades são produto do meio em que vivemos, são construçôes narrativas que a um só tempo influenciam e são influenciadas por nossa cultura. Isso fica claro quando Nicholson diz que não é mais possível fazermos afirmações sobre a identidade feminina baseados em algo dado, ou numa realidade imutável, mas precisamos reconhecer que nossas identidades "emergem de nossos próprios lugares na história e na cultura; são atos políticos que refletem os contextos de onde surgimos e os futuros que gostaríamos de ver" (Nicholson, 1995, p. 63).

\section{Ação política na pós-modernidade}

Mohanty (1995), Patton (1995) e Mouffe (1995) compartilham dessa visão pós-moderna da concepção de identidade. Mohanty (1995), por exemplo, critica a visão essencialista da categoria "mulher", uma visão que anula as diferenças sociais e históricas entre as mulheres e concebe a experiência da mulher como dada e individual. Para 
Mohanty, assim como para Nicholson (1995), definir a mulher em termos da diferença, do contraste homem/mulher, igualmente define a mulher em termos de sua uniformidade, ou seja, sua igualdade com todas as outras mulheres, sua essência. Essa visão ignora as diferentes influências históricas, culturais e sociais sofridas por mulheres em diferentes contextos. Além disso, ao ignorar a historicidade das diferentes experiências femininas, teorias feministas essencialistas limitam a noção de luta política. Essas teorias essencialistas baseiam a noção de luta política na suposição de que, universalmente, toda mulher sofre opressão masculina, e é essa opressão supostamente experienciada pelas mulheres de forma universal que as une numa "irmandade", num "espaço só para mulheres” (Mohanty, 1995, p. 79). Contudo, essa concepção universal da opressão feminina, como explica a autora, tende a excluir experiências femininas que são diferentes do padrão preconcebido. Para a autora, é necessário reconhecer que "a experiência do 'Eu', que é normalmente descontínua e fragmentada, deve ser historiciada antes que possa ser generalizada para uma visão coletiva” (p. 82). Partindo desse reconhecimento, Mohanty sugere que, em vez de se basear na suposta unicidade da experiência da mulher, a luta política feminista deve basear-se na noção de "coalizão", ou seja, uma noção da luta política em que as alianças são feitas em torno de objetivos específicos, ainda que temporários, com diferentes grupos de interesses possivelmente diversos.

Enfocando a luta por direitos civis para minorias excluídas, Patton (1995) também defende o "inessencialismo" identitário. Segundo ela, a posição essencialista assumida pelos movimentos identitários pós-anos de 1960 acabou por proporcionar reações conservadoras às demandas desses grupos, que foram consideradas "privilégios especiais”. A autora afirma que,

(...) embora a estratégia de ligar identidade, minoria, e direitos civis tenha obtido enorme sucesso em criar uma massa política e em atingir um status mais favorável para pelo menos alguns dos grupos da resistência, a habilidade de nomear e utilizar identidade não permaneceu sob o controle de movimentos identitários progressistas. A extrema direita finalmente reconheceu as demandas identitárias de homossexuais e feministas, mas com o objetivo de barrar sua inclusão no próprio discurso de direitos civis a que tais identidades pretendiam ter acesso. (p. 240-241)

Patton ressalta que o principal problema desses movimentos identitários essencialistas é que eles "acreditaram na promessa de direitos 
inalienáveis, direitos que estariam garantidos assim que [seu] status de sujeitos políticos fosse assegurado” (p. 241). E conclui que o desafio agora é encontrar maneiras de garantir espaço aos movimentos políticos, sejam eles essencialistas ou não, num contexto em que o significado de direitos políticos foi totalmente re-conceptualizado por interesses conservadores circunstanciais. Sobre isso, Nicholson (1995, p. 24) lembra que o trabalho de Patton (1995) "realça a questão de que categorias de análise são construtos sociais cujos significados e consequências se alteram em diferentes contextos”.

Por fim, Mouffe (1995) defende uma "política democrática radical". A autora claramente concorda com as ideias de Mohanty (1995) e Patton (1995) discutidas acima, quando diz que

Muitas feministas acreditam que, sem ver a mulher como uma identidade coerente, não podemos embasar a possibilidade de um movimento político feminista no qual as mulheres poderiam se unir como mulheres para formular e perseguir objetivos especificamente feministas. Contrariamente a essa visão, argumentarei que, para aquelas feministas que estão comprometidas com uma política democrática radical, a desconstrução de identidades essenciais deveria ser vista como a condição necessária para uma compreensão adequada da variedade de relaçôes sociais a que os princípios de liberdade e igualdade deveriam se aplicar. (Mouffe, 1995, p. 317-318)

Assim como Mohanty (1995), Mouffe acredita que não se pode falar em categorias homogêneas que contrapõem a identidade da "mulher" e do "homem". Para ela, nossas identidades estão baseadas numa "multiplicidade de relações sociais em que as diferenças sexuais são sempre construídas de formas muito diversas" (p. 319). Dentro dessa visão, fica claro que qualquer interpretação da identidade feminina como essência não consegue representar todas as possibilidades de experiências femininas. Como ressalta Nicholson (1995, p. 25), "não existe a 'mulher' em geral", mas qualquer mulher ocupa simultaneamente outras posições em termos de raça, classe social, preferência sexual ou nacionalidade. É a compreensão dessa identidade múltipla, fragmentada da mulher que permite, na visão de Mouffe (1995), assumir uma ação política em torno da noção de uma "identidade política coletiva" baseada no princípio de "liberdade e igualdade para todos" (p. 325). 


\section{Por uma ação política integral}

A proposta dessas autoras, principalmente Mohanty (1995) e Mouffe (1995), que sugerem estender a ação política dos movimentos identitários para além dos limites estabelecidos pela concepção essencialista de identidade, em busca de objetivos mais amplos, e em coalizão, ainda que temporariamente, com grupos de interesses diversos, parece se alinhar com o pensamento de Wilber $(2005,2007)$, que sugere uma abordagem integral da espiritualidade, um modelo que, segundo ele, é abrangente e inclusivo, estabelecendo um papel radicalmente novo para a espiritualidade e para a religião neste novo milênio.

$\mathrm{O}$ autor recorre, primeiramente, às ideias de Carol Gilligan que, no livro In a different voice, afirma que homens e mulheres pensam de forma diferente. Como explica Wilber (2005, p. 7), de acordo com Gilligan, "os homens raciocinam usando uma lógica de direitos, justiça e autonomia; mas as mulheres raciocinam usando uma lógica de amor, relacionamento e responsabilidade". Wilber esclarece, ainda, que Gilligan também observou que, embora o pensamento feminino seja mais relacional - em oposição ao pensamento masculino hierarquizado -, tanto homens quanto mulheres tendem a passar por três ou quatro estágios de desenvolvimento do pensamento moral. A esses estágios, segundo Wilber (2005, 2007), Gilligan denominou "egocêntrico, etnocêntrico, globocêntrico e integral". No primeiro estágio, egocêntrico, a moralidade humana estaria inteiramente centrada no "Eu". No segundo estágio, o pensamento moral do ser humano expande-se, centrando-se no "nós", e passa a incluir aqueles que são considerados parte do seu grupo, da sua tribo ou nação, daí esse estágio ser denominado etnocêntrico. No estágio três, ou globocêntrico, a noção de identidade do ser humano novamente se expande e seu pensamento moral inclui, então, "todos nós", ou "todos os seres humanos (ou, até mesmo, todos os seres sencientes)" (Wilber, 2007, p. 26). No quarto estágio, chamado de integral, a noção de identidade do ser humano seria expandida indefinidamente para todo o universo, daí sua integralidade.

É essa integralidade que Wilber $(2005,2007)$ sugere como sendo o novo papel da religião neste milênio. É também esse tipo de pensamento integral que seria necessário para que a luta política dos movimentos identitários, conforme sugerem Mohanty (1995), Patton (1995) e Mouffe (1995), deixasse de buscar objetivos essencialistas e 
atingisse um novo estágio - integral - em que "objetivos contingentes e conjuntamente construídos podem coexistir com as diferenças" (Nicholson \& Seidman, 1995, p. 12). Assim, em vez de lutar por objetivos que beneficiassem a "mulher", ou o "negro", ou os "homossexuais", compreendidos como um conjunto definido de características essenciais, esses movimentos tentariam formar alianças temporárias em torno de objetivos explícitos comuns.

Para que isso seja possível, é necessária uma compreensão das necessidades identitárias em relação à sua localidade, ou seja, seu contexto cultural em termos de uma nova noção de espaço. Como lembra Soja (1996, p. 1), "somos, e sempre fomos, seres intrinsecamente espaciais, participantes ativos na construção social de nossas espacialidades". Contudo, o autor também ressalta que a noção de espacialidade tem sido "relativamente periférica” nas ciências humanas. Para Soja, mesmo entre teóricos que assumem uma "perspectiva mais crítica e politicamente comprometida", os eventos sociais humanos, sejam eles individuais ou coletivos, são sempre abordados a partir de apenas dois pontos de vista: a dimensão histórica ou temporal e a dimensão social ou sociológica (p. 2). Soja não deseja reduzir a importância dessas duas dimensões para a teorização e a prática das ciências humanas, mas sim ressaltar "a simultaneidade e o complexo entrelaçamento do social, do histórico e do espacial, sua inseparabilidade e interdependência (...) o que começa a resultar em importantes revisões sobre como estudamos a história e a sociedade" (p. 3).

Soja (1996, p. 2) introduz, então, a noção de "terceiro espaço" como sendo, num sentido amplo, "um milieu de ideias, eventos, aparências e significados em constante movimento e mutação". É nesse espaço que podemos imaginar o desenvolvimento de perspectivas integrais (Wilber, 2005, 2007) de ação política para os movimentos identitários. Como o próprio Soja (1996, p. 5) define, terceiro espaço é

(...) um espaço de extraordinária abertura, um lugar de trocas críticas em que a imaginação geográfica pode ser expandida para incluir uma multiplicidade de perspectivas até então consideradas incompatíveis, incombináveis pelos juízes epistemológicos. É um espaço onde questões de raça, classe e gênero podem ser abordadas simultaneamente sem privilégio de uma sobre a outra (...).

Bhabha (2000) também aborda uma forma de terceiro espaço, híbrido e radical, que para ele é o espaço da resistência política das 
minorias reprimidas, em oposição às práticas culturais dominantes. $\mathrm{O}$ terceiro espaço é, assim, tanto para Soja (1996) quanto para Bhabha (2000, 2003), um espaço marginal, de contato ou tradução entre culturas ou identidades. É o espaço onde novas formas de ação e de interpretação se desenvolvem, onde se atinge uma compreensão da natureza híbrida das trocas interculturais (Bhabha, 2000).

Essa nova perspectiva somente pode ser alcançada por meio de uma compreensão e aceitação da perspectiva do "outro". Porém, só é possível compreender aquilo que já se sabe. Rubem Alves (2004, p. 28) retoma Nietzsche para nos dizer que "ninguém consegue tirar das coisas, incluindo os livros, mais do que aquilo que ele já conhece. Pois aquilo a que alguém não pode chegar por meio da experiência, para isso ele não terá ouvidos". É isso também que nos mostra Caetano Veloso, com a música Sampa, escrita em 1978 em homenagem à cidade de São Paulo, ao dizer: "Quando eu te encarei frente a frente não vi o meu rosto (...) / É que Narciso acha feio o que não é espelho (...)".

Nesses versos, Caetano Veloso nos ensina aquilo que já sabemos, mas nos recusamos a admitir: achamos "feio" tudo aquilo que nos é estranho ou desconhecido. Por isso, rejeitamos e excluímos o "outro", aquele que nos é estranho ou diferente. O terceiro espaço, conforme sugerido por Soja (1996) e Bhabha (2000, 2003), nos permitiria compreender a perspectiva do outro, pois é justamente onde a nossa perspectiva se funde com a perspectiva do outro, sem que seja possível distinguir uma da outra.

O filme em desenho animado Irmão urso, lançado pela Disney em 2003, traz um interessante exemplo desse momento singular, vivido por um menino que, como diz o próprio filme, "se transformou em homem ao se transformar em urso". Conforme informaçōes contidas no filme, a história é baseada em antigos mitos da região do Alaska e narra as aventuras de Kenai, "um jovem impulsivo que é transformado em urso [e] enquanto busca recuperar sua forma humana, aprende importantes liçôes de vida e conhece o mundo sob novas perspectivas".

No filme, Kenai e seus irmãos - Sitka e Denahi - brincam e pescam salmão nas águas geladas do rio próximo da aldeia onde vivem. Kenai está prestes a passar pelo ritual que lhe concederá a "maioridade". Um urso aproxima-se da aldeia e rouba os salmões que os irmãos tinham pescado. Os irmãos perseguem o urso, mas Sitka, o mais velho 
dos irmãos, é morto numa luta com o animal. Kenai resolve se vingar e parte em busca do animal, conseguindo matá-lo, numa violenta luta travada no alto de uma montanha. Depois disso, Kenai é transformado em urso num ritual de magia transcendental. Kenai, então, agora como urso, conhece Koda, um filhote de urso que está perdido e tenta reencontrar sua mãe. Os dois partem juntos, à procura de um lugar onde, segundo Koda, haveria uma grande reunião dos ursos, a Corrida Anual do Salmão. Ao chegar lá, Kenai e Koda se reúnem com outros ursos, à noite em torno da fogueira, para compartilhar histórias de suas experiências. É então que Kenai, sob a forma de urso, ouve Koda contar sua história: desde o momento em que "três monstros armados até os dentes" perseguem sua mãe, que o esconde num arbusto e foge em direção oposta, atraindo os monstros atrás de si, até o momento em que sua mãe cai no rio gelado e desaparece. Koda acha que sua mãe e ele apenas se desencontraram, mas acredita que ela vai voltar. Ao ouvir a história de Koda, contudo, Kenai lembra-se da luta de seu irmão Sitka com o urso - na verdade, a ursa mãe de Koda - e de como Sitka, já exausto, provocou uma avalanche na montanha para derrubar o urso e assim salvar os irmãos mais novos (Kenai e Denahi). Kenai e Denahi em vão vasculham o rio em busca de Sitka, que também caíra com a avalanche. Kenai também se lembra de sua própria luta com o urso e de como o havia matado. É por meio dessa história - a narrativa de Koda - que Kenai percebe que, para os ursos, os humanos são tão monstros quanto os ursos o são para os humanos. $\mathrm{O}$ mais interessante é que ele percebe isso justamente sob a perspectiva dos próprios ursos, pois fora transformado em urso.

Nesse momento singular, as identidades de Kenai-humano e Kenai-urso confundem-se e Kenai percebe-se múltiplo, híbrido. Mais que isso, ele percebe como ele e Koda, humano e urso, são parecidos, embora sejam tão diferentes. É a partir desse momento, a partir da criação desse terceiro espaço de percepção, que Kenai passa a compreender melhor a perspectiva de Koda e a sua própria identidade, ao mesmo tempo tão diferente e tão semelhante à sua imagem.

Com esse exemplo, vemos como é possível compreendermos a nós mesmos ao compreendermos o outro. Como nos falava o filósofo Ricoeur já nos anos de 1970 , em seu ensaio sobre o conflito das interpretações, "a função da interpretação é a de fazer coincidir a compreensão do outro - e de seus signos em múltiplas culturas - com a 
compreensão de si e do ser” (1978, p. 45). Assim, para Ricoeur, ao interpretar, o que perseguimos, por meio da compreensão do outro, é a ampliação de nossa própria compreensão a respeito de nós mesmos.

É nesse sentido que o terceiro espaço de que falam Soja (1996) e Bhabha $(2000,2003)$ é o espaço que devemos buscar atingir, se quisermos compreender tanto nossas próprias perspectivas quanto as perspectivas dos "outros", sob a ótica da multiplicidade, do hibridismo e da coalizão, como propõem os autores aqui discutidos. É essa ótica, dita pós-moderna, que nos permitirá avançar na luta política, em busca da almejada integralidade e de elementos que nos ajudem a melhor compreender nosso envolvimento diário na vida em comunidade, em todos os contextos, e a definir um desejável nível de comprometimento social.

\section{Recebido em junho de 2008 e aprovado em dezembro de 2008.}

\section{Notas}

1. Sobre a história de uma tartaruga e um hipopótamo. Disponível em: <www.contatodireto. fot.br>. Acesso em: 3 fev. 2008.

2. Tradução minha, assim como em todas as outras citações feitas a partir de fontes estrangeiras, no restante deste trabalho.

3. "Self" no original. Bruner (1990) usa a palavra sempre com a inicial maiúscula, provavelmente para salientar a importância do conceito. $\mathrm{O}$ mesmo não ocorre em outros trabalhos. Contudo, neste trabalho, optei por usar também a inicial maiúscula, já que em português a palavra é muito pequena para representar toda a amplitude que o conceito exige.

4. A palavra "Negras" encontra-se com letra maiúscula no texto original.

\section{Referências}

ALVES, R. Se eu pudesse viver minha vida novamente... Campinas: Verus, 2004.

BARRY, H. Jerome Bruner. Disponível em: <http://evolution.massey. ac.nz/assign2/HB/jbru-ner.html>. Acesso em: 17 jan. 2006.

BHABHA, H.K. The vernacular cosmopolitan. In: Dennis, F.; KHAN, N. (Org.). Voices of the crossing. London: Serpent's Tail, 2000. p. 133142. 
BHABHA, H.K. On writing rights. In: GiBnEY, M. (Ed.). Globalizing rights: the Oxford amnesty lectures. Oxford: Oxford University, 2003. p. 162-183.

BRUNER, J. Actual minds, possible worlds. Cambridge, Mass.: Harvard University Press, 1986.

BRUNER, J. Acts of meaning. Cambridge, Mass.: Harvard University Press, 1990.

BRUNER, J. Making stories: law, literature, life. Cambridge, Mass.: Harvard University Press, 2002.

CHANCE, K. The right to narrate: interview with Homi Bhabha. Disponível em: <http://www.bard.edu/hrp/resource_pdfs/chance.hbhabha. pdf>. Acesso em: 16 jul. 2007.

CORACINI, M.J. A celebração do Outro: arquivo, memória e identidade. Campinas: Mercado de Letras, 2007.

FIVUSH, R. Memory and narrative, self and voice. Disponível em: <http://narrative-matters.com/speakers.html>. Acesso em: $17 \mathrm{jan}$. 2006a.

FIVUSH, R. Family narratives project. Disponível em: <http:// psychology.emory.edu/cogni-tion/fivush/lab/Family\%20Narrative. htm>. Acesso em: 17 jan. 2006b.

MOHANTY, C.T. Feminist encounters: locating the politics of experience. In: Nicholson, L.; Seidman, S. (Org.). Social postmodernism: beyond identity politics. Cambridge, Mass.: Cambridge University, 1995. p. 68-86.

MOUFFE, C. Feminism, citizenship, and radical democratic politics. In: Nicholson, L.; Seidman, S. (Org.). Social postmodernism: beyond identity politics. Cambridge: Cambridge University, 1995. p. 315-331.

NICHOLSON, L. Interpreting gender. In: Nicholson, L.; SeIDMAN, S. (Org.). Social postmodernism: beyond identity politics. Cambridge, Mass.: Cambridge University, 1995. p. 39-67.

NICHOLSON, L.; SEIDMAN, S. (Org.). Social postmodernism: beyond identity politics. Cambridge, Mass.: Cambridge University, 1995. 
PATTON, C. Refiguring social space. In: Nicholson, L.; Seidman, S. (Org.). Social postmodernism: beyond identity politics. Cambridge, Mass.: Cambridge University, 1995. p. 216-249.

RICOEUR, P. O conflito das interpretaçôes: ensaios de hermenêutica. Rio de Janeiro: Imago, 1978.

RUTHERFORD, J. The third space: interview with Homi Bhabha. In: Rutherford, J. (Org.). Changing identities: community, culture, difference. London: Lawrence \& Wishart, 1990. p. 207-221.

SESHADRI-CROOKS, K. Surviving theory: a conversation with Homi K. Bhabha. In: Afzal-Khan, F.; Seshadri-Crooks, K. (Org.). The preoccupation of postcolonial studies. London: Duke University, 2000. p. 369-379.

SOJA, E.W. Third space: journeys to Los Angeles and other real-andimagined places. Oxford: Blackwell, 1996.

SPELMAN, E. Inessential woman: problems of exclusion in feminist thought. Boston: Beacon, 1988.

WILBER, K. A sociable God: toward a new understanding of religion. Boston; London: Shambala, 2005.

WILBER, K. Espiritualidade integral: uma nova função para a religião neste início de milênio. São Paulo: Aleph, 2007. 